\section{Obstruktive Hypopnoe}

Helga Peter

Marburg, Deutschland

\section{Englischer Begriff}

obstructive hypopnea

\section{Definition}

Verminderung des Luftflusses an Mund und Nase um mindestens $30 \%$ und maximal $89 \%$ des Ausgangsniveaus. Die
Verminderung tritt im Schlaf auf, dauert mindestens zehn Sekunden und ist durch eine Obstruktion im Bereich der extrathorakalen Atemwege bedingt. Die Atmungsanstrengungen der Atemmuskulatur sind weiterhin vorhanden. Im zeitlichen Zusammenhang mit der Verminderung des Luftflusses tritt entweder eine Sauerstoffentsättigung um mindestens $3 \%$ oder ein EEG-Arousal auf.

Siehe auch

- „Schnarchen“

- „Atmungsmessung“ 